\title{
Dose-Response Effects of an Aqueous Formulation of Calcitriol and Evaluation of Renal Function in Nonpregnant Cows
}

\author{
Danil KIM ${ }^{1,2)}$, Norio YAMAGISHI ${ }^{1,2) *}$, Yuji KAWAKAMI ${ }^{2)}$, Izumi ABE ${ }^{3)}$, Kazuhisa FURUHAMA ${ }^{1,2)}$, \\ Bhuminand DEVKOTA ${ }^{2,4)}$, Kouya SASAKI ${ }^{1,2)}$, Norimoto OKURA ${ }^{5}$, Shigeru SATO ${ }^{1,2)}$ and Shuichi OHASHI ${ }^{3)}$ \\ 1) United Graduate School of Veterinary Sciences, Gifu University, 1-1 Yanagido, Gifu, Gifu 501-1193, Japan \\ ${ }^{2)}$ Department of Veterinary Medicine, Faculty of Agriculture, Iwate University, 3-18-8 Ueda, Morioka, Iwate 020-8550, Japan \\ 3)Nippon Zenyaku Kogyo Co., Ltd., 1-1 Tairanoue, Koriyama, Fukushima 963-0196, Japan \\ 4) Institute of Agriculture and Animal Science, Tribhuvan University, Chitwan, Nepal \\ 5) Biei Veterinary Clinical Center, Kamikawa Chuo Agricultural Mutual Aid Association, Kamikawagun, Hokkaido 071-0200, Japan
}

(Received 1 August 2011/Accepted 30 October 2011/Published online in J-STAGE 11 November 2011)

ABSTRACT. Dose responses of plasma calcitriol, calcium (Ca), bone metabolic markers and glomerular filtration rate (GFR) were evaluated in four nonpregnant Holstein cows treated subcutaneously with an aqueous formulation of calcitriol at four doses in a $4 \times 4$ Latin-square design. Calcitriol, $\mathrm{Ca}$, and markers of bone metabolism were analyzed in plasma samples. GFR was measured in predose and day 5 samples. Plasma calcitriol and Ca concentrations increased dose-dependently. The calcitriol dose was positively correlated with the area under the concentration-time curve of plasma calcitriol. Bone formation markers tended to increase from day 3 onward for all doses. No significant changes in GFR were noted. Thus, exogenous calcitriol administered between $0.0625 \mathrm{and} 0.5 \mu \mathrm{g} / \mathrm{kg}$ body weight elicited dose-dependent increases in both plasma calcitriol and $\mathrm{Ca}$ and elevated bone formation markers without affecting renal function in nonpregnant cows.

KEY WORDS: calcitriol, calcium, dairy cows, dose response, glomerular filtration rate.

doi: 10.1292/jvms.11-0363; J. Vet. Med. Sci. 74(4): 473-476, 2012

No veterinary formulations of 1,25-dihydroxyvitamin $D_{3}$ (calcitriol) have been developed for use in bovine medicine; however, it has been suggested that exogenous calcitriol may be useful in the prevention of postpartum hypocalcemia in cows $[6,7]$. When developing a drug for wide application in bovine medicine, scientific data regarding the effects and properties of the pharmaceutical agent after administration in cattle are essential. In our previous studies on testing calcitriol formulation and administration routes in nonpregnant cows, no evident differences were detected in pharmacokinetic parameters between subcutaneous and intramuscular administration [10, 11]. However, we concluded that the oleaginous formulation of calcitriol was not appropriate, especially in cattle, because of some disadvantages including an inhibitory effect on endogenous calcitriol synthesis and a tendency to cause drug residue problems at the injection site [6, 11]. Meanwhile, treatments with aqueous calcitriol at a dose of 0.5 $\mu \mathrm{g} / \mathrm{kg}$ of body weight (BW) exceeded the physiologically acceptable plasma calcitriol concentration until $24 \mathrm{hr}$ post treatment [10]. While this supraphysiological calcitriol concentration was effective in increasing the plasma calcium $(\mathrm{Ca})$ level, the risk of adverse effects such as reduced glomerular filtration rate (GFR) was of concern [4]. It was,

*Correspondence to: Yamagishi, N., Department of Veterinary Medicine, Faculty of Agriculture, Iwate University, Morioka, Iwate 020-8550, Japan.

e-mail: yamagisi@iwate-u.ac.jp

(C)2012 The Japanese Society of Veterinary Science therefore, important to perform further studies to examine the dose response to exogenous aqueous calcitriol, with simultaneous monitoring of plasma calcitriol, plasma $\mathrm{Ca}$ and renal function in nonpregnant cows. On the other hand, although endogenous calcitriol is known to stimulate bone resorption together with parathyroid hormone [6, 13], we observed that exogenous calcitriol treatment stimulated the biosynthesis of osteocalcin (OC), a bone formation marker, and decreased the levels of bone resorption markers shortly after the concentration of plasma Ca peaked in nonpregnant cows $[10,11]$. Hence, in order to clarify the mechanism of action of exogenous aqueous calcitriol on bone tissue, an evaluation of its effects on bone metabolic markers in normocalcemic dairy cows was also necessary.

The objectives of the present study were to evaluate the dose responses of plasma calcitriol, $\mathrm{Ca}$, and bone metabolic markers to a single injection of an aqueous formulation of calcitriol in cattle. In addition, GFR, blood urea nitrogen (BUN) and creatinine (CRE) were also evaluated to assess adverse effects of exogenous calcitriol treatment on renal tissue.

The study protocol was approved by the Iwate University Laboratory Animal Care and Use Committee. Four nonpregnant, nonlactating Holstein cows ranging from 4.8 to 6.4 years in age and from 680 to $800 \mathrm{~kg}$ in BW were reared in free stalls at the Iwate University Farm (Morioka, Japan). The cows were fed grass hay ad libitum with $2 \mathrm{~kg}$ of commercial concentrate, which supplied approximately $47.8 \mathrm{~g}$ of $\mathrm{Ca}$ and $26.7 \mathrm{~g}$ of phosphorus daily. To prepare the aqueous formulation, calcitriol $(25 \mu \mathrm{g} / \mathrm{m} l$, Mercian, 

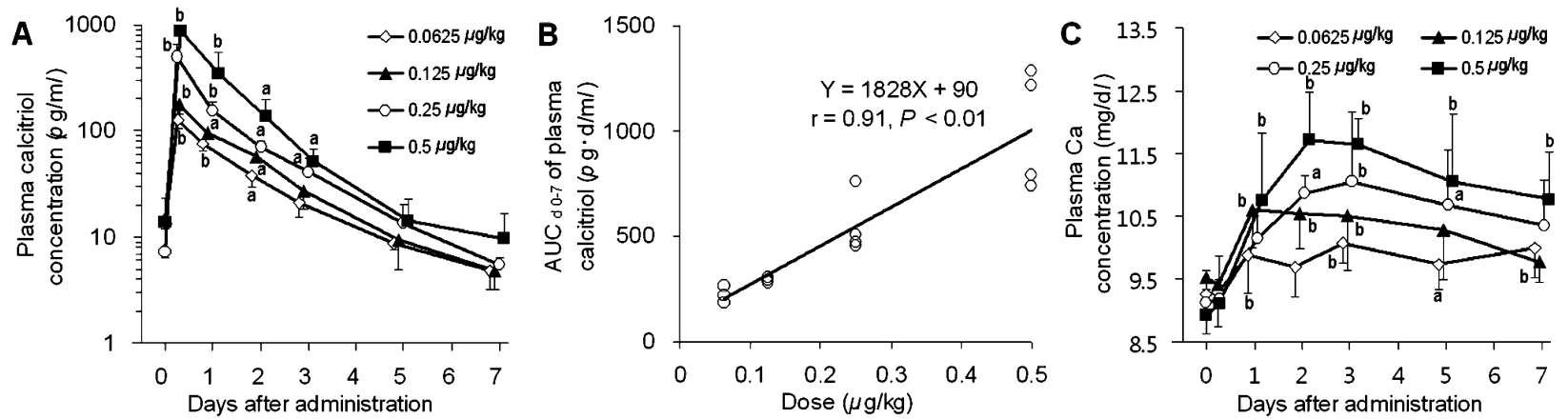

Fig. 1. (A) Changes in plasma calcitriol concentrations in four cows treated subcutaneously with different doses of calcitriol. (B) Linear correlation between the doses of calcitriol and area under the concentration-time curve from day 0 to $7\left(\mathrm{AUC}_{\mathrm{d} 0-7}\right)$ of plasma calcitriol $(\mathrm{r}=0.91, P<0.01)$. (C) Changes in plasma calcium $(\mathrm{Ca})$ concentrations in four cows treated subcutaneously with different doses of calcitriol. The values represent means $\pm \mathrm{SD}$. Significant differences in comparison with the predose value are denoted by the letters a $(P<0.05)$ and $\mathrm{b}(P<0.01)$.

Tokyo, Japan) was dissolved in an aqueous solution $(\mathrm{pH}$ 7.2) containing $0.14 \mathrm{mM}$ butylhydroxytoluene, $1.5 \mathrm{mM}$ of polysorbate $80,11.6 \mathrm{mM}$ trisodium citrate, $59 \mathrm{mM}$ sodium dihydrogen phosphate dihydrate and $25.7 \mathrm{mM}$ sodium chloride, as described previously [8]. Before calcitriol treatment, all four cows were treated with the vehicle to generate control data. According to a $4 \times 4$ Latin square design, the cows were then treated subcutaneously with calcitriol at a dose of $0.0625,0.125,0.25$ or $0.5 \mu \mathrm{g} / \mathrm{kg} \mathrm{BW}$. Doses were chosen based on previous studies $[10,16]$. An interval of at least 2 weeks elapsed between treatments. The dosing day was regarded as day 0 in each treatment. Heparinized blood samples were collected from the jugular vein of each cow just prior to calcitriol administration (predose) and at $6 \mathrm{hr}$ and 1, 2, 3, 5 and 7 days post treatment. Blood samples were centrifuged immediately, and plasma was separated and stored at $-50^{\circ} \mathrm{C}$ until it was analyzed.

Calcitriol and $\mathrm{Ca}$ concentrations in plasma were measured in all samples as previously reported [10]. The area under the concentration-time curve from days 0 to 7 $\left(\mathrm{AUC}_{\mathrm{d} 0-7}\right)$ for plasma calcitriol was calculated by the linear trapezoidal rule with extrapolation. Bone formation markers, including undercarboxylated $\mathrm{OC}$ (ucOC) and OC concentrations, and bone-resorption markers, including tartrate-resistant acid phosphatase isoform 5b (TRAP5b) and hydroxyproline (HYP), were determined in predose samples and on days 1, 3, 5 and 7, as previously described [10]. GFR, BUN and CRE were compared in cows prior to calcitriol treatment and at day 5. To measure GFR, the contrast medium iodixanol (VISIPAQUE 320; $320 \mathrm{mg} \mathrm{I} / \mathrm{ml}$, Daiichi-Sankyo, Tokyo, Japan) was infused into the jugular vein at a dose of $20 \mathrm{mg} \mathrm{I} / \mathrm{kg} \mathrm{BW}$, and blood was drawn 1, 2 and $3 \mathrm{hr}$ later. The serum iodixanol concentration was measured by high performance liquid chromatography [9]. GFR values were corrected by an empirically determined formula [2] and presented in $\mathrm{m} l / \mathrm{min} / \mathrm{kg}$. BUN and CRE were measured by an enzymatic colorimetric method using an Accute TBA-40FR autoanalyzer (Toshiba, Tokyo, Japan).
All numerical data are expressed as means \pm standard deviation (SD). Repeated measures (RM) analysis of variance (ANOVA) on ranks, followed by the Student-Newman-Keuls test, was applied to analyze changes in plasma calcitriol concentrations in each treatment. The Pearson product-moment correlation test was performed to determine the relationship between the dose of calcitriol and $\mathrm{AUC}_{\mathrm{d} 0-7}$. One-way RM ANOVA followed by Dunnett's method was used to analyze changes in plasma Ca concentrations and bone metabolic markers. Paired $t$-tests were performed to compare predose and day 5 parameters of renal function. Significance was set at $P<0.05$. These analyses were carried out using SigmaStat for Windows, version 3.5 (Systat software Inc., San Jose, CA, U.S.A.).

In cows given the vehicle control, no changes were seen in the levels of plasma calcitriol or $\mathrm{Ca}$, or in bone metabolic markers, during the sampling period.

Treatment of cows with a series of calcitriol doses caused the plasma calcitriol concentration and its $\mathrm{AUC}_{\mathrm{d} 0-7}$ to be elevated in a dose-dependent manner (Fig. 1A and 1B). Although supraphysiological concentrations of plasma calcitriol (over $250 \mathrm{pg} / \mathrm{ml}$ ) [5, 7] were induced by treatment with 0.25 or $0.5 \mu \mathrm{g} / \mathrm{kg}$ calcitriol, we could not detect an inhibitory effect on endogenous calcitriol synthesis, such as significant decrease in plasma calcitriol concentration as compared to the predose values, as was observed in our previous study that tested the effect of oleaginous calcitriol [11]. Moreover, calcitriol did not affect any renal function parameters on day 5 (GFR, 1.9-2.2 $\mathrm{ml} / \mathrm{min} / \mathrm{kg}$; BUN, 6.4-8.6 mg/d ; CRE, 0.8-0.9 $\mathrm{mg} / \mathrm{d} l$ ) even in cows receiving 340-400 $\mu \mathrm{g}$ calcitriol $(0.5 \mu \mathrm{g} / \mathrm{kg})$. Goff et al. [4] reported that GFR was reduced by treatment with $400 \mu \mathrm{g}$ calcitriol at 5-6 days post-treatment in nonpregnant Jersey cows that appeared to have received $0.8-1.0 \mu \mathrm{g} / \mathrm{kg}$ calcitriol [4]. Thus, the amount of calcitriol did not seem to be high enough to cause impaired renal function in our cows, and reduced GFR seems to be associated with the dosage level of calcitriol. Breed could be another reason for the discrepancy; Jersey cows are known to be more susceptible 

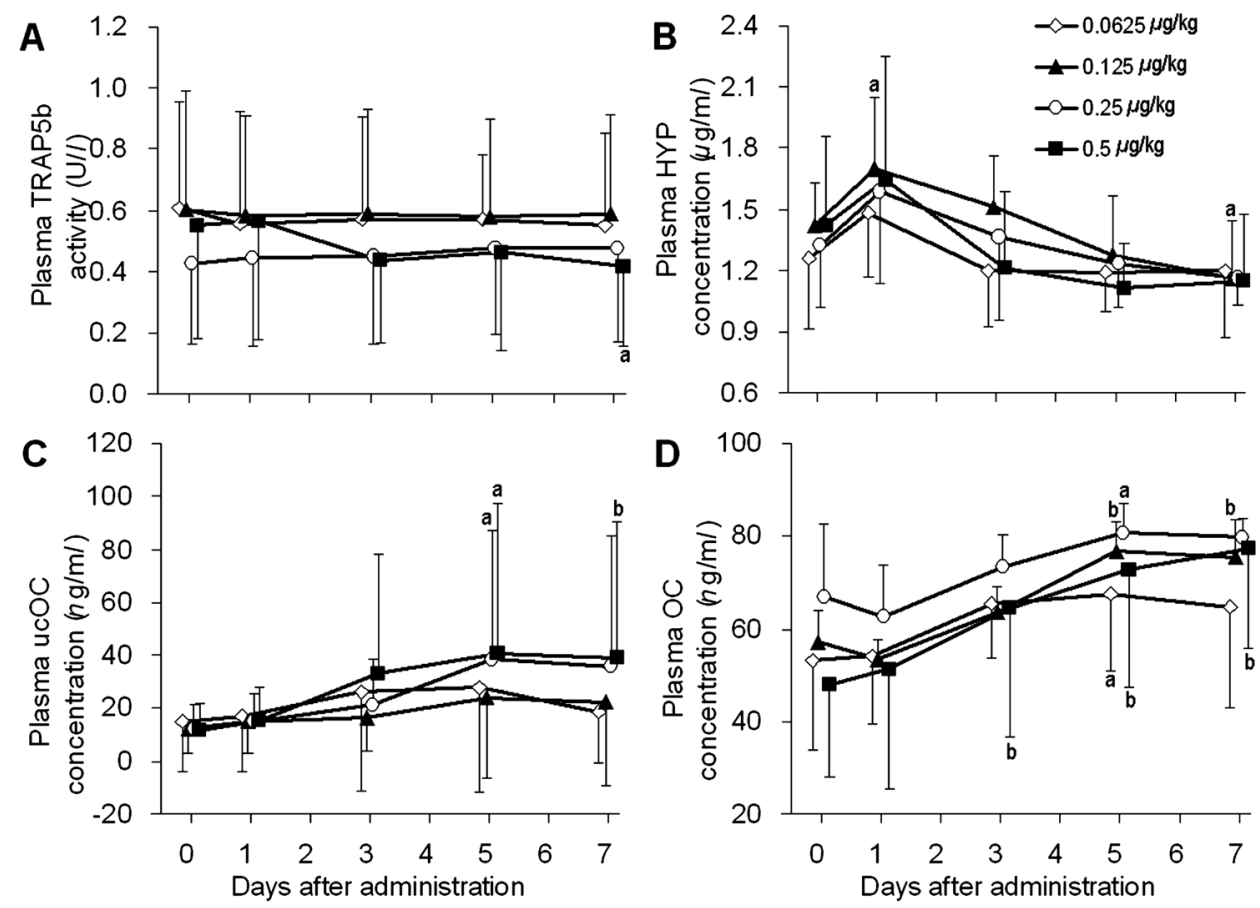

Fig. 2. Changes in bone metabolic markers in four dairy cows treated subcutaneously with four different doses of calcitriol. (A) Tartrate-resistant acid phosphatase isoform 5b (TRAP5b). (B) Hydroxyproline (HYP). (C) Undercarboxylated osteocalcin (ucOC). (D) Osteocalcin (OC). The values represent means \pm SD. Significant differences in comparison with the predose value are denoted by the letters a $(P<0.05)$ and $\mathrm{b}(P<0.01)$.

to hypocalcemic disorder than Holstein cows [6].

Peak plasma Ca concentrations following calcitriol administration were increased dose-dependently (Fig. 1C), which is consistent with previous studies $[4,16]$. In cows given $0.125,0.25$ and $0.5 \mu \mathrm{g} / \mathrm{kg}$ calcitriol, significantly increased plasma $\mathrm{Ca}$ concentrations compared with the predose levels were maintained until day $3(10.5 \pm 0.9 \mathrm{mg} / \mathrm{d} l)$, $5(10.7 \pm 0.9 \mathrm{mg} / \mathrm{d} l)$ and $7(10.8 \pm 0.8 \mathrm{mg} / \mathrm{d} l)$, respectively, without any clinical signs associated with hypercalcemia. These findings indicate that the dosage level of calcitriol is positively correlated with the period of hypercalcemia, as well as its magnitude. In ewes [1] and cows [15], the hypercalcemic effect of calcitriol or its analogues has been reported to be dependent upon intestinal $\mathrm{Ca}$ absorption and an upregulation of intestinal transcellular active $\mathrm{Ca}$ transport, a process requiring about $24 \mathrm{hr}$ after calcitriol administration. In the present study, plasma Ca concentrations were elevated significantly on day 1 at all doses of calcitriol, and further increases in $\mathrm{Ca}$ concentration from day 1 to day 2 were remarkable with high doses of calcitriol $(P<0.05$ with $0.5 \mu \mathrm{g} / \mathrm{kg}, P<0.1$ with $0.25 \mu \mathrm{g} / \mathrm{kg}$; Paired $t$ test; data not shown). These data imply that elevation of the plasma Ca concentration from day 1 to day 2 may be due to the genomic activation of transcellular active $\mathrm{Ca}$ transport in the intestine $[1,15]$, which could be induced by treatment with 0.25 and $0.5 \mu \mathrm{g} / \mathrm{kg}$ calcitriol in nonpregnant cattle.

While reporting the potential usefulness of calcitriol for the prevention of postpartum hypocalcemia, some limitations such as a difficulty in determining the timing of injection and delayed development of hypocalcemia have been proposed $[4,6,7,11]$. Calcitriol has to be injected at an optimal time because of its short half-life in the body. In order to resolve this problem, long-acting calcitriol formulations, such as 24-fluoride-calcitriol [4] and the oleaginous formulation of calcitriol [11], were studied. However, these formulations induced adverse reactions similar to those of a high dose level of calcitriol. In particular, oleaginous calcitriol showed a more potent hypercalcemic effect than the aqueous formulation and also significantly decreased the plasma calcitriol concentration [11]. In addition, delayed development of hypocalcemia in parturient cows given calcitriol may be caused by the inhibitory effect of a supraphysiological calcitriol level on endogenous calcitriol synthesis following treatment with a high dose of calcitriol. Therefore, these limitations may be resolved with repeated administration of the aqueous calcitriol at doses lower than $0.25 \mu \mathrm{g} / \mathrm{kg}$, which can be one of the strategies for the prevention of postpartum hypocalcemia using calcitriol. Because pregnant cows were reported to be more sensitive to vitamin D treatment than nonpregnant cows [14], it is not clear whether these dose levels of calcitriol can be applied equally in pregnant cows. Thus, the hypercalcemic effect of calcitriol observed in the present study might be induced with a lower dosage in pregnant cows, and further studies 
are needed to confirm this hypothesis. Evaluation of the hypercalcemic effect of repeated injection of calcitriol is also indispensable.

TRAP5b activity was decreased only in cows treated with the highest dose of calcitriol, on day 7 (Fig. 2A), and fluctuations in HYP levels were significant only in cows treated with $0.125 \mu \mathrm{g} / \mathrm{kg}$ calcitriol, on days 1 and 7 (Fig. 2B). While the plasma concentration of ucOC increased significantly on day 5 and on days 5 to 7 in cows given 0.25 and $0.5 \mu \mathrm{g} / \mathrm{kg}$ calcitriol, respectively (Fig. 2C), the plasma OC concentrations increased at all doses of calcitriol (Fig. 2D). Plasma HYP concentration and TRAP5b activity are known to reflect the activity of osteoclasts and the number of osteoclasts, respectively $[3,4]$. Thus, our results suggest that osteoclastic activity in cows treated with any dose of calcitriol tended to decrease from day 1 and that the number of osteoclasts decreased only in cows given $0.5 \mu \mathrm{g} / \mathrm{kg}$ calcitriol on day 7. This suppressive effect on bone resorption may be due to hypercalcemia resulting from decreased secretion of parathyroid hormone or increased secretion of calcitonin or both. In addition, we previously reported that exogenous calcitriol stimulated the biosynthesis of OC in nonpregnant cows $[10,11]$, whereas we could not detect its dose-dependency in the present study, probably due to large individual variation. However, the results of OC suggest that osteoblasts of calcitriol-treated cows synthesize new OC upon stimulation by the lowest dose of calcitriol administered in this experiment [12] and that redundant plasma $\mathrm{Ca}$ might be removed by the accretion into bone with OC.

In conclusion, dose-dependent increases in plasma calcitriol and $\mathrm{Ca}$ concentrations as well as dose-dependent extension of the hypercalcemic period were induced by a single subcutaneous injection of the aqueous calcitriol without affecting renal function in nonpregnant Holstein cows. These data strongly suggest that the aqueous formulation of calcitriol can be applied safely at doses up to 0.5 $\mu \mathrm{g} / \mathrm{kg} \mathrm{BW}$ in nonpregnant cows.

\section{REFERENCES}

1. Braithwaite, G. D. 1978. The effect of 1- $\alpha$-hydroxycholecalciferol on calcium and phosphorus metabolism in the lactating ewe. $\mathrm{Br}$. J. Nutr. 40: 387-392. [CrossRef] [Medline]

2. Bröchner-Mortensen, J. 1972. A simple method for the determination of glomerular filtration rate. Scand. J. Clin. Lab. Invest. 30: 271-274. [CrossRef] [Medline]

3. Chu, P., Chao, T. Y., Lin, Y. F., Janckila, A. J. and Yam, L. T. 2003. Correlation between histomorphometric parameters of bone resorption and serum type $5 \mathrm{~b}$ tartrate-resistant acid phosphatase in uremic patients on maintenance hemodialysis.
Am. J. Kidney Dis. 41: 1052-1059. [CrossRef] [Medline]

4. Goff, J. P., Horst, R. L., Littledike, E. T., Boris, A. and Uskokovic, M. R. 1986. Bone resorption, renal function and mineral status in cows treated with 1,25-dihydroxycholecalciferol and its 24-fluoro analogues. J. Nutr. 116: 1500-1510. [Medline]

5. Horst, R. L., Eisman, J. A., Jorgensen, N. A. and DeLuca, H. F. 1977. Adequate response of plasma 1,25-dihydroxyvitamin D to parturition in paretic (milk fever) dairy cows. Science 196 662-663. [CrossRef] [Medline]

6. Horst, R. L., Goff, J. P. and Reinhardt, T. A. 1994. Calcium and vitamin D metabolism in the dairy cow. J. Dairy Sci. 77: 1936-1951. [CrossRef] [Medline]

7. Hove, K., Horst, R. L. and Littledike, E. T. 1983. Effects of $1 \alpha$-hydroxyvitamin $\mathrm{D}_{3}, 1,25$-dihydroxyvitamin $\mathrm{D}_{3}$, 1,24,25-trihydroxyvitamin $\mathrm{D}_{3}$, and 1,25,26-trihydroxyvitamin $\mathrm{D}_{3}$ on mineral metabolism and 1,25-dihydroxyvitamin D concentrations in dairy cows. J. Dairy Sci. 66: 59-66. [CrossRef] [Medline]

8. Isobe, T., Takahashi, M., Kubota, A. and Horii, I. 1995. Studies on toxicity of calcitriol injectable (8): hemolysis test (Human blood) and local irritation test (Rabbits). Jpn. Pharmacol. Ther. 23: S1447-S1456 (in Japanese with English abstract).

9. Jacobsen, P. B., Blindheim, L. and Skotland, T. 1995. Bioanalytical methods for iodixanol and their application to studies on metabolism and protein binding. Acta Radiol. Suppl. 399: 61-66. [Medline]

10. Kim, D., Kawakami, Y., Yamagishi, N., Abe, I., Furuhama, K., Okura, N., Sato, S. and Ohashi, S. 2011. Response of plasma bone markers to a single intramuscular administration of calcitriol in dairy cows. Res. Vet. Sci. 90: 124-126. [CrossRef] [Medline]

11. Kim, D., Yamagishi, N., Abe, I., Furuhama, K., Devkota, B. and Ohashi, S. 2011. Effects of an oleaginous calcitriol on changes in plasma calcitriol, calcium and bone metabolic markers in dairy cows. J. Vet. Med. Sci. 73: 185-191. [CrossRef] [Medline]

12. Lee, A. J., Hodges, S. and Eastell, R. 2000. Measurement of osteocalcin. Ann. Clin. Biochem. 37: 432-446. [CrossRef] [Medline]

13. Liesegang, A., Eicher, R., Sassi, M. L., Risteli, J., Kraenzlin, M., Riond, J. L. and Wanner, M. 2000. Biochemical markers of bone formation and resorption around parturition and during lactation in dairy cows with high and low standard milk yields. J. Dairy Sci. 83: 1773-1781. [CrossRef] [Medline]

14. Littledike, E. T. and Horst, R. L. 1982. Vitamin D toxicity in dairy cows. J. Dairy Sci. 65: 749-759. [CrossRef] [Medline]

15. Naito, Y., Goff, J. P., Horst, R. L. and Reinhardt, T. A. 1989. Effects of continuous administration of 1,25-dihydroxyvitamin $\mathrm{D}_{3}$ on plasma minerals and unoccupied colon mucosal 1,25-dihydroxyvitamin $\mathrm{D}_{3}$ receptor concentrations. J. Dairy Sci. 72: 2936-2941. [CrossRef] [Medline]

16. Okura, N., Yamagishi, N., Naito, Y. and Koiwa, M. 2007. Dose response to vaginal administration of 1,25-dihydroxyvitamin $\mathrm{D}_{3}$ to cows. Vet. J. 174: 203-205. [CrossRef] [Medline] 